Annals of Pure and Applied Mathematics

Vol. 13, No. 2, 2017, 199-206

ISSN: 2279-087X (P), 2279-0888(online)

Published on 7 April 2017

www.researchmathsci.org

DOI: http://dx.doi.org/10.22457/apam.v13n2a5

$\overline{\text { Annals of }}$

Pure and Applied

Mathematics

\title{
3-Equitable and Total Magic Cordial Labeling for the Extended Duplicate Graph of Splitting Graph of Path
}

\author{
R.Avudainayaki ${ }^{1}$, B.Selvam ${ }^{2}$ and P.P.Ulaganathan ${ }^{3}$ \\ ${ }^{1}$ Department of Mathematics, Sri Sairam Institute of Technology \\ Chennai - 600044 India \\ ${ }^{2,3}$ Department of Mathematics, S.I.V.E.T. College, Gowrivakkam \\ Chennai - 600 073, India \\ Email: avuramesh2004@gmail.com; ppulaganathan@gmail.com \\ Corresponding author. Email: kbmselvam@gmail.com \\ Received 9 March 2017; accepted 28 March 2017
}

Abstract. In this paper, we prove that the extended duplicate graph of splitting graph of path admits 3-equitable and total magic cordial labeling.

Keywords: Graph labeling, duplicate graph, splitting graph, 3-equitable, total magic cordial

\section{AMS Mathematics Subject Classification (2010): $05 \mathrm{C} 78$}

\section{Introduction}

All graphs in this paper are simple, finite and undirected. The vertex set and edge set of a graph is denoted by $\mathrm{V}(\mathrm{G})$ and $\mathrm{E}(\mathrm{G})$ respectively. If the vertices of the graph are assigned values subject to certain conditions then it is known as graph labeling. A useful survey to know about the numerous labeling methods is by Gallian [5]. Sampathkumar has introduced the concept of duplicate graph [4]. A new labeling called total Magic cordial labeling and 3-equitable labeling introduced by Cahit [3], Girija and Elumalai have proved that the edge magic total labeling of the cycle $\mathrm{C}_{n}$ with $\mathrm{p}_{3}$ chords [8]. Thirusangu, Selvam and Ulaganathan have proved that the total magic cordial labeling for the extended duplicate graph of twig graphs [2]. Sutha, Thirusangu and Bala have proved that the some graph labelings on middle graph of extended duplicate graph of a path [6]. Thirusangu, Ulaganathan and Vijaya kumar have proved that the some cordial labeling of duplicate graph of ladder graph [7]. Mary et al. have proved that the Labelings on jahangir graph and extended duplicate graph of Jahangir graph [10]. Graph labelings have many applications within mathematics as well as to several areas of computer science and communication networks. Kalantari, Khosrovshahi and Mitchell [1,9] tried to find applications of magic labeling in optimisation theory, especially for the travelling salesmen problem. In this paper, we prove that the existence of extended duplicate graph of splitting graph of path admits 3 -equitable and total magic cordial labeling. 
R.Avudainayaki, B.Selvam and P.P.Ulaganathan

\section{Preliminaries}

In this section, we give the basic definitions relevant to this paper. Let $\mathrm{G}(\mathrm{V}, \mathrm{E})$ be a finite, simple and undirected graph with $\mathrm{p}$ vertices and q edges.

Definition 2.1. (Splitting graph) For each vertex $\mathrm{v}$ of a graph $\mathrm{G}$, take a new vertex $v^{\prime}$. Join $v^{\prime}$ to all the vertices of $\mathrm{G}$ adjacent to $v$. The graph $\operatorname{Spl}(\mathrm{G})$ thus obtained is called splitting graph of $\mathrm{G}$.

\section{Illustration 1. (The splitting graph of path $\operatorname{Spl}\left(\mathbf{P}_{6}\right)$ )}

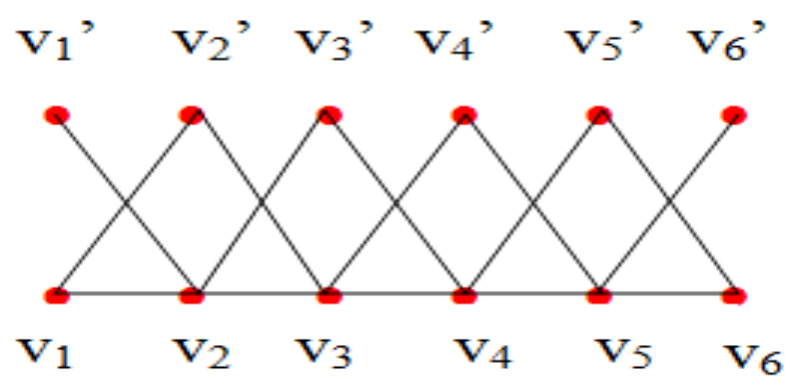

Figure 1:

Definition 2.2. (Duplicate graph) Let $\mathrm{G}(\mathrm{V}, \mathrm{E})$ be a simple graph and the duplicate graph of $\mathrm{G}$ is $\mathrm{DG}=\left(\mathrm{V}_{1}, \mathrm{E}_{1}\right)$, where the vertex set $\mathrm{V}_{1}=\mathrm{V} \cup \mathrm{V}^{\prime}$ and $\mathrm{V} \cap \mathrm{V}^{\prime}=\phi$ and $f: \mathrm{V} \rightarrow \mathrm{V}^{\prime}$ is bijective (for $v \in \mathrm{V}$, we write $f(v)=v^{\prime}$ for convenience) and the edge set $\mathrm{E}_{1}$ of DG is defined as the edge $a b$ is in $\mathrm{E}$ if and only if both $a b^{\prime}$ and $a b$ are edges in $\mathrm{E}_{1}$.

Definition 2.3. (Extended duplicate graph of splitting graph of path) Let DG = $\left(V_{1}, E_{1}\right)$ be a duplicate graph of splitting graph of path $G(V, E)$. Extended duplicate graph of splitting graph of path is obtained by adding the edge $\mathrm{V}_{2} \mathrm{~V}_{2}$ ' to the duplicate graph. It is denoted by EDG Spl $\left(\mathrm{P}_{\mathrm{m}}\right)$. Clearly it has $4 \mathrm{~m}$ vertices and $6 \mathrm{~m}-5$ edges, where $m \geq 2$ is the number of length.

Illustration 2. Extended duplicate graph of splitting graph of a path

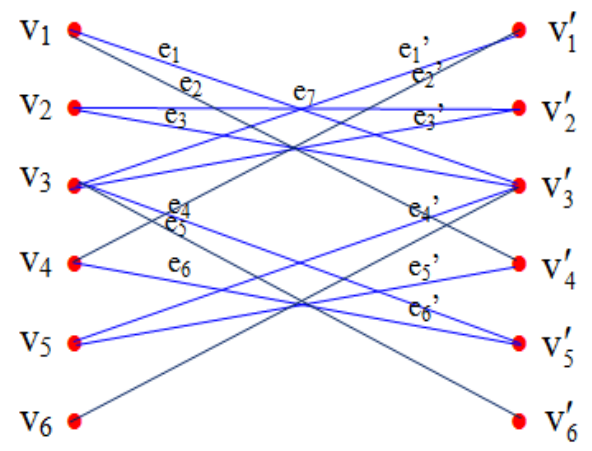

Figure 2: $\operatorname{EDG}\left(\operatorname{Spl}\left(P_{3}\right)\right)$ 
3-Equitable and Total Magic Cordial Labeling for the Extended Duplicate Graph of Splitting Graph of Path

Definition 2.5. (3-equitable labeling) A function $f: \mathrm{V} \rightarrow\{0,1,2\}$ such that each edge $u v$ receives the label $|f(u)-f(v)|$ is said to be 3-equitable labeling if $\left|v_{f}(i)-v_{f}(j)\right| \leq 1$ and $\left|e_{f}(i)-e_{f}(j)\right| \leq 1$ for all $0 \leq i, j \leq 2$.

Definition 2.6. (Total magic cordial labeling) A graph $\mathrm{G}(\mathrm{V}, \mathrm{E})$ is said to admit total total magic cordial labeling if $f: \mathrm{V} \cup \mathrm{E} \rightarrow\{0,1\}$ such that

$(i)\{f(x)+f(y)+f(x y)\}(\bmod 2)$ is constant for all edges $x y \in \mathrm{E}$.

(ii) $|f(0)-f(1)| \leq 1$, where

a) $f(0)$ denotes the sum of the number of the vertices labeled with ' 0 ' and the number of edges labeled with ' 0 '.

b) $f(1)$ denotes the sum of the number of the vertices labeled with ' 1 ' and the number of edges labeled with ' 1 '.

\section{Main results}

Algorithm 3.1.

Procedure [3-Equitable labeling for $\operatorname{EDG}\left(\operatorname{Spl}\left(\mathbf{P}_{m}\right)\right), m \geq 2$ ]

$$
\begin{aligned}
& \mathrm{V} \leftarrow\left\{\mathrm{v}_{1}, \mathrm{v}_{2}, \ldots, \mathrm{v}_{2 \mathrm{~m}}, \mathrm{v}_{1}{ }_{1}, \mathrm{v}_{2}{ }_{2}, \ldots, \mathrm{v}^{\prime}{ }_{2 \mathrm{~m}}\right\} \\
& \mathrm{E} \leftarrow\left\{\mathrm{e}_{1}, \mathrm{e}_{2}, \ldots, \mathrm{e}_{3 \mathrm{~m}-3}, \mathrm{e}_{3 \mathrm{~m}-2}, \mathrm{e}^{\prime}{ }_{1}, \mathrm{e}_{2}, \ldots, \mathrm{e}{ }_{3 \mathrm{~m}-3}\right\} \\
& v_{1} \leftarrow 1, v_{2} \leftarrow 1, v^{\prime}{ }_{1} \leftarrow 2, v_{2} \leftarrow 0 \\
& \text { for } \mathrm{i}=0 \text { to }[(\mathrm{m}-2) / 3] \mathbf{d o} \\
& v_{3+6 \mathrm{i}} \leftarrow 0 \\
& v_{4+6 \mathrm{i}} \leftarrow 0 \\
& v_{{ }_{3+6 \mathrm{i}}} \leftarrow 1 \\
& v^{\prime}{ }_{4+6 \mathrm{i}} \leftarrow 2
\end{aligned}
$$$$
\mathrm{E} \leftarrow\left\{\mathrm{e}_{1}, \mathrm{e}_{2}, \ldots, \mathrm{e}_{3 \mathrm{~m}-3}, \mathrm{e}_{3 \mathrm{~m}-2}, \mathrm{e}_{1}, \mathrm{e}_{2}, \ldots, \mathrm{e}^{\prime}{ }_{3 \mathrm{~m}-3}\right\}
$$

end for

$$
\text { for } \begin{aligned}
& \mathrm{i}=0 \text { to }[(\mathrm{m}-3) / 3] \text { do } \\
& v_{5+6 \mathrm{i}} \leftarrow 2 \\
& v_{6+6 \mathrm{i}} \leftarrow 0 \\
& v^{\prime}{ }_{5+6 \mathrm{i}} \leftarrow 2 \\
& v^{\prime}{ }_{6+6 \mathrm{i}} \leftarrow 1
\end{aligned}
$$

end for

for $\mathrm{i}=0$ to $[(\mathrm{m}-4) / 3] \mathbf{d o}$

$$
\begin{aligned}
& v_{7+6 \mathrm{i}} \leftarrow 1 \\
& v_{8+6 \mathrm{i}} \leftarrow 1 \\
& v_{7+6 \mathrm{i}}^{\prime} \leftarrow 2 \\
& v_{8+6 \mathrm{i}}^{\prime} \leftarrow 0
\end{aligned}
$$




\section{R.Avudainayaki, B.Selvam and P.P.Ulaganathan}

end for

\section{end procedure}

Theorem 3.1. The extended duplicate graph of splitting path graph $\operatorname{Spl}\left(\mathrm{P}_{\mathrm{m}}\right), \quad \mathrm{m} \geq 2$ admits 3-equitable labeling.

Proof: Let $\operatorname{Spl}\left(P_{m}\right), \mathrm{m} \geq 2$ be a splitting path graph . In order to label the vertices, define a function $f: \mathrm{V} \rightarrow\{0,1,2\}$ as given in algorithm 3.1.

The vertices $v_{1}, v_{2}, v_{1}$ ' and $v_{2}$ ' receive label ' 1 ', ' 1 ' , '2' and ' 0 ' respectively ;

for $0 \leq \mathrm{i} \leq[(\mathrm{m}-2) / 3]$, the vertices $v_{3+6 \mathrm{i}}$ receive label ' 0 '; the vertices $v_{4+6 \mathrm{i}}$ receive label ' 0 '; the vertices $v^{\prime}{ }_{3+6 \mathrm{i}}$ receive label ' 1 '; the vertices $v^{\prime}{ }_{4+6 \mathrm{i}}$ receive label '2' ;

for $0 \leq \mathrm{i} \leq[(\mathrm{m}-3) / 3]$, the vertices $v_{5+6 \mathrm{i}}$ receive label ' 2 ' ; the vertices $v_{6+6 \mathrm{i}}$ receive label ' 0 '; the vertices $v^{\prime}{ }_{5+6 \mathrm{i}}$ receive label ' 2 ' ' and the vertices $v^{\prime}{ }_{6+6 \mathrm{i}}$ receive label ' 1 '; for $0 \leq \mathrm{i} \leq[(\mathrm{m}-4) / 3]$, the vertices $v_{7+6 i}$ receive label ' 1 ' ; the vertices $v_{8+6 \mathrm{i}}$ receive label ' 1 '; the vertices $v_{7+6 i}^{\prime}$ receive label ' 2 '; the vertices $v_{8+6 i}^{\prime}$ receive label ' 0 ' ;

Thus, the entire $4 \mathrm{~m}$ vertices are labeled.

To obtain the labels for edges, we define the induced function $\mathrm{f}^{*}: \mathrm{E} \rightarrow\{0,1,2\}$ such that $\mathrm{f} *\left(v_{\mathrm{i}} v_{\mathrm{j}}\right)=\left|f\left(v_{\mathrm{i}}\right)-f\left(v_{\mathrm{j}}\right)\right|$ where $v_{\mathrm{i}}, v_{\mathrm{j}} \in \mathrm{V}$

The induced function yields the label ' 0 ' for the edges $\mathrm{e}_{1}, \mathrm{e}_{3}, \mathrm{e}_{3}$; the label ' 1 ' for the edges $\mathrm{e}_{2}, \mathrm{e}_{3 \mathrm{~m}-2}$; the label ' 2 ' for the edges $\mathrm{e}_{1}$ and $\mathrm{e}_{2}$;

for $0 \leq \mathrm{i} \leq[(\mathrm{m}-3) / 3]$ and $0 \leq \mathrm{j} \leq 1$, the edges $\mathrm{e}_{4+9 i+2 \mathrm{j}}$ receive label ' 2 '; the edges $\mathrm{e}_{5+9 \mathrm{i}}$ receive label ' 1 '; the edges $e^{\prime}{ }_{4+9 i+j}$ receive label ' 1 '; the edges e' ${ }_{6+9 i}$ receive label ' 0 ' ;

for $0 \leq \mathrm{i} \leq[(\mathrm{m}-4) / 3]$ and $0 \leq \mathrm{j} \leq 1$, the edges $\mathrm{e}_{7+9 \mathrm{i}}$ receive label ' 0 ' ; the edges $\mathrm{e}_{8+9 i+\mathrm{j}}$ receive label ' 0 '; the edges $e^{\prime}{ }_{7+9 i+j}$ receive label ' 1 ' ; the edges e' ${ }_{9+9 i}$ receive label ' 0 ';

for $0 \leq \mathrm{i} \leq[(\mathrm{m}-5) / 3]$ and $0 \leq \mathrm{j} \leq 1$, the edges $\mathrm{e}_{10+9 \mathrm{i}+2 \mathrm{j}}$ receive label ' 0 ' ; the edges $\mathrm{e}_{11+9 \mathrm{i}}$ receive label ' 1 ' ; the edges e' ${ }_{10+9 \mathrm{i}+\mathrm{j}}$ receive label ' 2 ' ; the edges e' ${ }_{12+9 \mathrm{i}}$ receive label ' 0 ';

case (i) If (m-2)mod $3=0$, then $2 \mathrm{~m}-1$ edges receive label ' 0 ', $2 \mathrm{~m}-2$ edges receive label ' 1 ' and $2 \mathrm{~m}-2$ edges receive label ' 2 ';

case (ii) If (m-2)mod $3 \neq 0$, then $2 \mathrm{~m}-1$ edges receive label ' 1 ', $2 \mathrm{~m}-2$ edges receive label ' 2 ' and $2 \mathrm{~m}-2$ edges receive label ' 0 ';

Thus in both the cases all the $6 \mathrm{~m}-5$ edges are labeled.Hence the extended duplicate graph of splitting path graph $\operatorname{Spl}\left(\mathrm{P}_{\mathrm{m}}\right), \mathrm{m} \geq 2$ is 3-equitable labeling.

Illustration 3. 3-equitable labeling for edg of spilitting graph of path. 
3-Equitable and Total Magic Cordial Labeling for the Extended Duplicate Graph of Splitting Graph of Path

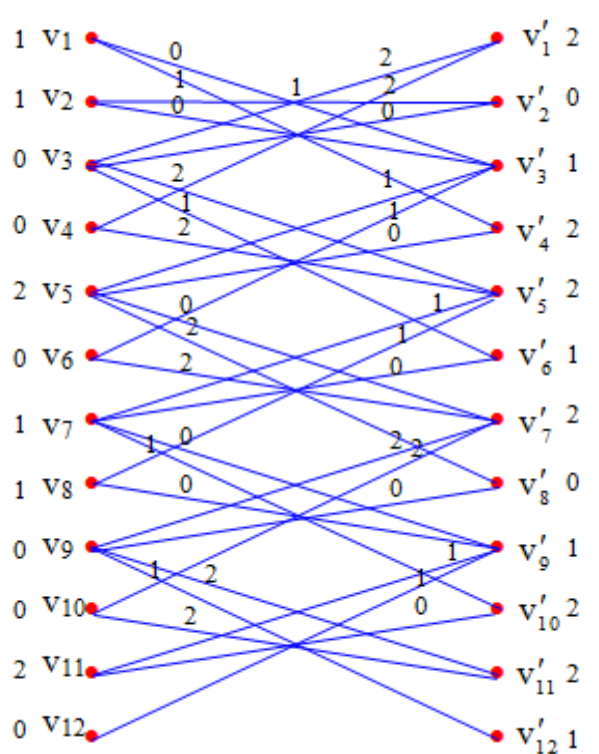

(a) $\operatorname{EDG}\left(\operatorname{Spl}\left(P_{6}\right)\right)$

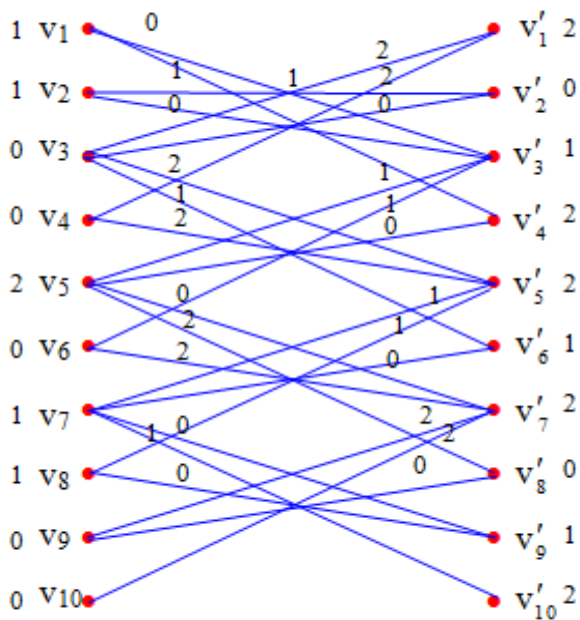

(b) $\operatorname{EDG}\left(\operatorname{Spl}\left(\boldsymbol{P}_{5}\right)\right)$

Figure 3:

\subsection{Total magic cordial labeling}

Algorithm 3.2.

Procedure[Total magic cordial labeling for $\left.\left(\operatorname{Spl}\left(\mathbf{P}_{m}\right)\right), m \geq 2\right]$

$$
\begin{gathered}
\mathrm{V} \leftarrow\left\{\mathrm{v}_{1}, \mathrm{v}_{2}, \ldots, \mathrm{v}_{2 \mathrm{~m}}, \mathrm{v}_{1}^{\prime}, \mathrm{v}^{\prime}{ }_{2}, \ldots, \mathrm{v}^{\prime}{ }_{2 \mathrm{~m}}\right\} \\
\mathrm{E} \leftarrow\left\{\mathrm{e}_{1}, \mathrm{e}_{2}, \ldots, \mathrm{e}_{3 \mathrm{~m}-3}, \mathrm{e}_{3 \mathrm{~m}-2}, \mathrm{e}^{\prime}, \mathrm{e}^{\prime}{ }_{2}, \ldots, \mathrm{e}^{\prime}\right. \\
v_{1} \leftarrow 1, \quad v_{2} \leftarrow 1, e_{3 \mathrm{~m}-2} \leftarrow 1 \\
v^{\prime}{ }_{1} \leftarrow 0, v^{\prime} \leftarrow 0 \\
\text { for } \mathrm{i}=0 \text { to }[(\mathrm{m}-2) / 2] \text { do } \\
v_{3+4 \mathrm{i}} \leftarrow 1 \\
v_{4+4 \mathrm{i}} \leftarrow 0 \\
v^{\prime}{ }_{3+4 \mathrm{i}} \leftarrow 1 \\
v^{\prime}{ }_{4+4 \mathrm{i}} \leftarrow 0
\end{gathered}
$$$$
\mathrm{E} \leftarrow\left\{\mathrm{e}_{1}, \mathrm{e}_{2}, \ldots, \mathrm{e}_{3 \mathrm{~m}-3}, \mathrm{e}_{3 \mathrm{~m}-2}, \mathrm{e}_{1}, \mathrm{e}_{2}, \ldots, \mathrm{e}^{\prime}{ }_{3 \mathrm{~m}-3}\right\}
$$

end for

for $\mathrm{i}=0$ to $[(\mathrm{m}-3) / 2]$ do

$$
\begin{aligned}
& v_{5+4 i} \leftarrow 1 \\
& v_{6+4 i} \leftarrow 1 \\
& v^{\prime}{ }_{5+4 i} \leftarrow 0 \\
& v^{\prime}{ }_{6+4 i} \leftarrow 0
\end{aligned}
$$

end for

for $\mathrm{i}=0$ to $[(\mathrm{m}-2) / 2]$ do 


\section{R.Avudainayaki, B.Selvam and P.P.Ulaganathan}

end for

$$
\begin{aligned}
& e_{1+6 \mathrm{i}} \leftarrow 0 \\
& e_{2+6 \mathrm{i}} \leftarrow 1 \\
& e_{3+6 \mathrm{i}} \leftarrow 0 \\
& e^{{ }_{1+6 \mathrm{i}}} \leftarrow 1 \\
& e^{e_{2+6 \mathrm{i}}} \leftarrow 0 \\
& e^{e^{\prime}{ }_{3+6 \mathrm{i}}} \leftarrow 1
\end{aligned}
$$

for $\mathrm{i}=0$ to $[(\mathrm{m}-3) / 2] \mathbf{d o}$

$$
\begin{aligned}
& e_{4+6 \mathrm{i}} \leftarrow 1 \\
& e_{5+6 \mathrm{i}} \leftarrow 1 \\
& e_{6+6 \mathrm{i}} \leftarrow 0 \\
& e^{\prime}{ }_{4+6 \mathrm{i}} \leftarrow 0 \\
& e^{\prime}{ }_{5+6 \mathrm{i}} \leftarrow 0 \\
& e^{\prime}{ }_{6+6 \mathrm{i}} \leftarrow 1
\end{aligned}
$$

end for

\section{end procedure}

Theorem 3.2. The extended duplicate graph of splitting path graph $\operatorname{Spl}\left(\mathrm{P}_{\mathrm{m}}\right), \quad \mathrm{m} \geq 2$ admits total magic cordial labeling.

Proof: Let $\operatorname{Spl}\left(P_{m}\right), \mathrm{m} \geq 2$ be a splitting path graph. In order to label the vertices and edges, define a function $f: \mathrm{V} \mathrm{UE} \rightarrow\{0,1\}$ as given in algorithm 3.2.

The vertices $v_{1}, v_{2}, v^{\prime}{ }_{1}, v_{2}$ ' and $e_{3 m-2}$ receive label ' 1 ' , ' 1 ' , ' 0 ' ,' 0 ' and ' 1 'respectively ; for $0 \leq \mathrm{i} \leq[(\mathrm{m}-2) / 2]$, the vertices $v_{3+4 \mathrm{i}}$ receive label ' 1 ' ; the vertices $v_{4+4 \mathrm{i}}$ receive label ' 0 '; the vertices $v^{\prime}{ }_{3+4 i}$ receive label ' 1 ' and the vertices $v^{\prime}{ }_{4+4 i}$ receive label ' 0 '; for $0 \leq \mathrm{i} \leq[(\mathrm{m}-3) / 2]$, the vertices $v_{5+4 \mathrm{i}}$ receive label ' 1 '; the vertices $v_{6+4 i}$ receive label ' 1 '; the vertices $v^{\prime}{ }_{5+4 \mathrm{i}}$ receive label ' 0 '; the vertices $v^{\prime}{ }_{6+4 \mathrm{i}}$ receive label ' 0 ';

for $0 \leq \mathrm{i} \leq[(\mathrm{m}-2) / 2]$, the edges $e_{1+6 \mathrm{i}}$ receive label ' 0 '; the edges $\mathrm{e}_{2+6 \mathrm{i}}$ receive label ' 1 '; the edges $e_{3+6 i}$ receive label ' 0 '; the edges $e_{1+6 i}$ receive label ' 1 ' ; the edges $e^{\prime}{ }_{2+6 \mathrm{i}}$ receive label ' 0 '; the edges $e^{\prime}{ }_{3+6 \mathrm{i}}$ receive label ' 1 ';

for $0 \leq \mathrm{i} \leq\left[(\mathrm{m}-3 / 2]\right.$, the edges $e_{4+6 \mathrm{i}}$ receive label ' 1 '; the edges $e_{5+6 \mathrm{i}}$ receive label ' 1 '; the edges $\mathrm{e}_{6+6 \mathrm{i}}$ receive label ' 0 '; the edges $e^{\prime}{ }_{4+6 \mathrm{i}}$ receive label ' 0 '; the edges $e^{\prime}{ }_{5+6 \mathrm{i}}$ receive label ' 0 '; the edges $e_{6+6 \mathrm{i}}$ receive label ' 1 ';

Thus all the $6 \mathrm{~m}-5$ edges are labeled.

The induced function $\mathrm{f} *: \mathrm{V} \mathrm{U} \mathrm{E} \rightarrow\{0,1\}$ is defined as $\mathrm{f} *\left(v_{\mathrm{i}} v_{\mathrm{j}}\right)=\left\{f\left(v_{\mathrm{i}}\right)+f\left(v_{\mathrm{j}}\right)+f\left(v_{\mathrm{i}}\right.\right.$ $\left.\left.v_{\mathrm{j}}\right)\right\}(\bmod 2) ; v_{\mathrm{i}} v_{\mathrm{j}} \in \mathrm{E}$ 
3-Equitable and Total Magic Cordial Labeling for the

Extended Duplicate Graph of Splitting Graph of Path

Thus the induced function yields the total magic cordial constant ' 0 '.

Hence the extended duplicate graph of splitting path graph $\left.S p l P_{m}\right), \quad \mathrm{m} \geq 2$ admits total magic cordial labeling.

illustration 4. Total magic cordial labeling for edg of spilitting graph of path

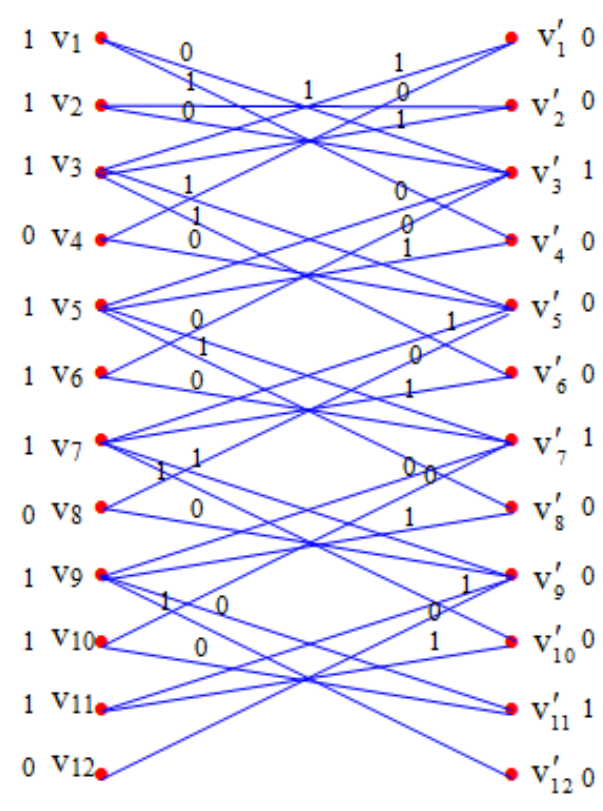

(a) $\operatorname{EDG}\left(\operatorname{Spl}\left(P_{6}\right)\right)$

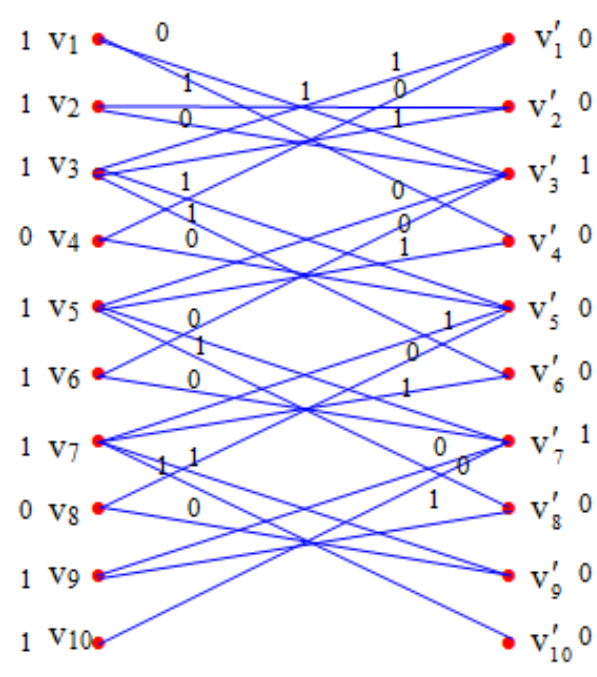

(b) $\operatorname{EDG}\left(\operatorname{Spl}\left(P_{5}\right)\right)$

Figure 4:

\section{Conclusion}

In this paper, we presented algorithms and prove that the extended duplicate graph of splitting graph path $\operatorname{Spl}\left(\mathrm{P}_{\mathrm{m}}\right), \mathrm{m} \geq 2$ admits 3-equitable and total magic cordial labeling.

\section{REFERENCES}

1. B.Kalantari and G.B. Khosrovshahi, Magic labeling in graphs: Bounds, complexity, and an application to a variant of TSP, Networks, 28(4) (1996) 211-219.

2. M.Pal, Intersection graphs: An introduction, Annals of Pure and Applied Mathematics, 4(1) (2013) 43-91.

3. I.Cahit, On cordial and 3-equitable labelings of graphs, Util. Math., 37 (1990) 189198.

4. E.Sampathkumar, On duplicate graphs, Journal of the Indian Math. Soc., 37 (1973) $285-293$.

5. G.A.Gallian, A dynamic survey of graph labeling, Electronic Journal of Combinatories, 19, \# DS6 (2015) 189-198. 
R.Avudainayaki, B.Selvam and P.P.Ulaganathan

6. K.Sutha, K.Thirusangu and S.Bala, Some graph labelings on middle graph of extended duplicate graph of a path, Annals of Pure and Applied Mathematics, 8(2) (2014) 169-174.

7. K.Thirusangu, P.P.Ulaganathan and P.Vijayakumar, Some cordial labeling of duplicate graph of ladder graph, Annals of Pure and Applied Mathematics, 8(2) (2014) 43-50.

8. L.Girija and A.Elumalai, Edge magic total labeling of the cycle $\mathrm{C}_{\mathrm{n}}$ with $\mathrm{P}_{3}$ Chords, Annals of Pure and Applied Mathematics, 8(2) (2014) 175-181.

9. T.Mitchell and B.Kalantari, Magic labeling and its relationship to the traveling salesmen problem, DIMACSREU, Summer (2001).

10. V.Celin Mary, K.Thirusangu and S.Bala, Extended duplicate graph of jahangir graph, Annals of Pure and Applied Mathematics, 8(2) (2014) 143-151.

11. S.Paul, M.Pal and A.Pal, L(2,1)-labeling of interval graphs, Journal of Applied Mathematics and Computing, 49 (1-2) (2015) 419-432. 